\title{
GALLO, Guadalupe; SEMÁN, Pablo (org.). 2016. Gestionar, mezclar, habitar: claves en los emprendimientos musicales contemporáneos. Ciudad Autónoma de Buenos Aires: Gorla. 256 p.
}

\author{
ELTON COLINI GONÇALVES ZIMMERMANN
}

UNIVERSIDADE FEDERAL DO PARANÁ (UFPR), CURITIBA/PR, BRASIL

HTTPS://ORCID.ORG/0000-0003-02I6-OI3I

Uma das maiores dificuldades de se trabalhar com fenômenos da juventude é a tendência que esses têm de, no mesmo momento em que são apreendidos, escaparem por entre os dedos daquelas e daqueles que buscaram compreendê-los. Já é bem conhecida a justa crítica feita à antropologia por durante muito tempo ter-se apoiado no fato objetivo da persistência física e geográfica de coletivos humanos para analiticamente excluir sua dimensão temporal, forjando aquilo que usamos chamar "presente etnográfico". Tal ficção da escrita faz esses coletivos parecerem repousar em presente contínuo. Dificilmente crítica semelhante se faz necessária aos trabalhos que se debruçam sobre as sociedades que se entendem por ocidentais ou modernas, em especial quando seu foco de interesse são fenômenos da juventude. Sendo quase consensualmente entendida como um produto histórico dentro de uma conformação social definida, a própria ideia de juventude carrega em si o sentido da transitividade, do porvir. Falar de "juventude" praticamente demanda um demarcador temporal que a localize: fala-se da juventude "de hoje", "dos anos oitenta" ou mesmo "de amanhâ". Ainda assim, há sempre um alto risco de se tribalizar épocas, de forma que, ainda que salvaguardando a historicidade da juventude, se a esvazie de sua dinâmica. Dessa forma, é interessante que os trabalhos que buscam acompanhá-la resistam à tentação de fazê-lo desde um ponto de vista estático, de aplicação de fórmulas que podem inclusive ter sido extraídas com muita felicidade de fenômenos juvenis da noite passada.

É esse positivo esforço que encontramos em Gestionar, mezclar, habitar: claves en los emprendimientos musicales contemporáneos, obra organizada por Guadalupe Gallo e Pablo Semán, e lançado em 2016 pela Editora Gorla. Resultado de mais de dez anos de pesquisa de uma equipe liderada pelo antropólogo argentino com formação no PPGAS da UFRGS ${ }^{1}$, o livro, que conta também com trabalhos de Ornella Boix e Victoria Irisarri, além das contribuições dos organizadores, busca fornecer subsídios para a compreensão dos cenários de produção e consumo de música na Argentina na contemporaneidade. Inicialmente, nos conta Pablo Semán, na Introdução, pesquisador e pesquisadoras se debruçaram sobre diferentes cenários de produção e consumo de música, buscando uma espécie de atualização nas correlações

1 Veja também a entrevista com Pablo Semán apresentada na Campos 19(2) 2018. http://dx.doi.org/10.5380/cra.v19i2.58142. 
entre classe e gosto musical na Argentina contemporânea. Confrontada com a irrelevância da pergunta - pois encontraram respostas a questões que ainda estavam por ser elaboradas - a equipe assumiu que, para além do fato da apreciação dos gêneros (que logo também seriam postos em cheque) já não ser tão facilmente circunscrita socialmente, a própria ideia de gosto era insuficiente para descrever as múltiplas formas dos sujeitos da pesquisa se relacionarem com a música.

Após deixarem em suspenso as questões de gabinete, ainda que iluminadas pela melhor literatura, os autores assumem, no decorrer das pesquisas, uma postura etnográfica que privilegia o ouvir ao demandar. O esforço que fazem, citando Antoine Hennion (2002), é no sentido de evitar a produção de uma sociologia que vá “contra os atores", ou seja, de evitar a produção de um conhecimento sobre os contextos sociais sobre os quais se debruçam que tenha, ainda que implicitamente, qualquer pretensão pedagógica frente aos atores que ali se encontram. Isso, evidentemente, não implica a crença em um descritivismo ingênuo, que suporia pesquisador e pesquisadoras transparentes no processo da pesquisa e da escrita. $\mathrm{O}$ que implica, sim, é uma postura de humildade e autovigilância que mantém os investigadores na posição de quem ouve. Tampouco implica a abstenção do autor e das autoras de refletirem e produzirem conhecimento que ultrapasse a mera idiossincrasia. Como fazem questão de deixar claro, o livro, tendo partindo de três campos empíricos situados na província de Buenos Aires, buscar ir além e tentar apreender ao menos os contornos da singularidade histórica registrada. Tal singularidade se caracterizaria pelo declínio de consolidadas formas de produzir e consumir música mais centradas na atuação da grande indústria, acompanhado da emergência de novas formas, mais horizontais e, ao menos em parte, protagonizadas pelos "prosumidores" de música. Misturar, Gerir e Habitar, surgem, na experiência das pesquisas, como três chaves conceituais auxiliares na compreensão desse contexto.

No primeiro dos três capítulos etnográficos, escrito por Ornela Boix e intitulado "Relajar, Gestionar y Editar: Haciendo música 'indie’ em la ciudad de La Plata”, a atenção da autora está voltada para as formas como a gestão foi incorporada ao rol de atividades inerentes à atuação dos músicos na cena musical indie da capital da província de Buenos Aires. Nele, Boix descreve um contexto em que jovens músicos passam a assumir também responsabilidades que em outros momentos seriam atribuídas a terceiros, tais como produtores, empresários, publicitários, técnicos, entre outros profissionais não diretamente ligados à atividade criativa. Essa incorporação foi, por um lado, possibilitada pela ampliação ao acesso a ferramentas de produção musical ocasionada pelo avanço tecnológico nessa área e, por outro, estimulada pelo desejo de manter-se independente de terceiros (sobretudo gravadoras) que tal tecnologia permitiu sustentar.

A autora nos mostra como ao contexto apresentado se relaciona uma estética que demonstra certa predileção pelo lo-fi (de low fidelity, som de baixa fidelidade) como uma espécie de indicativo de autenticidade das produções, sejam gravadas ou ao vivo, quase como uma marca dos dedos de seus autores no produto final. Longe de idealizarem o lo-fi, porém, seja como preferência estética, seja como manifesto político, os interlocutores de Boix estão mais atentos às condições de possibilidade que levam a esta configuração. Em outras palavras, tais músicos estão preocupados com a moralidade subjacente ao lo-fi, a de sujeitos relajados cujas produções/apresentações não se guiam por critérios alheios de avaliação, especialmente aqueles relacionados a interesses de sucesso comercial de personagens como empresários de gravadoras ou de casas noturnas. 
Através da organização de selos, uma série de mediações são realizadas, nesse contexto. Neles, busca-se não apenas a conciliação das funções de músicos e gestores, mas também o equilíbrio de outras equações. São eles que permitem alguma produtividade na cena, no sentido de serem os loci de articulação de diferentes atores sociais que, através deles, fazem coisas (gravam discos, divulgam-nos, organizam shows, articulam a música com atividades de diferentes expressões artísticas), possibilitando uma rentabilidade mínima aos músicos, sem, contudo, incorrerem na profissionalização que poderia ser vista como danosa à sua autonomia artística. Não é à toa que o modo básico de relação dentro dos (e entre os) selos seja o da amizade. Mas amizade aí assume um sentido que, antes do afeto e do compartilhamento da intimidade (dela, evidentemente, não excluídos em potência), repousa sobre proximidades estéticas e éticas, característica recorrente em contextos de sociabilidade juvenil contemporânea marcados por projetos coletivos.

A amizade como mediadora de relações entre os sujeitos de empreendimentos musicais é algo visível no capítulo de Guadalupe Gallo, intitulado "Noches sin igual: el club de baile em la escena electrónica porteña”, sobre uma casa noturna de música eletrônica de Buenos Aires. Tal como no contexto do indie rock platense, reservadas as diferenças etnográficas, aqui também surgem, no campo, questões referentes à oscilação entre comércio e arte, profissionalismo e amadorismo, consumo e experiência, que as relações de trabalho entre amigos buscam equacionar. Embora parte dos interlocutores de Gallo tenda a enfatizar apenas um dos polos dessas equações, conforme a posição que assumem no cenário geral, o que percebemos é uma etnografia cuidadosa, que entende o campo como local de múltiplas vocalizações (e silenciamentos) que nem sempre caminham no mesmo sentido, mas dão lugar a disputas, tensões e contradições frequentemente não resolvidas. Tentar ouvir essas vozes e depreender delas o que o campo fala sem simplesmente justapor as falas ou eleger aquela mais representativa ou significativa é uma tarefa difícil a que Gallo enfrenta com qualidade, fazendo bom uso da experiência etnográfica.

No contexto do livro aqui resenhado, o capítulo escrito por Gallo ocupa o espaço dedicado ao conceito-chave habitar. Como nos demais capítulos, a reflexão acontece dentro de um quadro etnográfico amplo que a autora constrói sobre um clube/casa de dança frequentado por clubbers da capital argentina. A autora nos mostra como foi apenas a partir de uma visita ocasional à Tacna, a casa em questão, durante o dia e não à noite, que ela começou a compreender como a relação que os sujeitos constroem com o espaço é muito mais que de apenas frequentação. A Tacna era uma casa e aqueles que a ela concorriam, habitavam-na, em vários sentidos. Evidentemente, habitar, aqui não se refere a endereço de residência, mas à forma dos sujeitos ali se colocarem. Cada noite na Tacna era única à medida em que ela se constituía em muito mais que a simples realização de um planejamento/programação previamente estabelecido. Como uma obra aberta, a casa permitia que seus habitués tomassem parte na construção das noites (o que ia desde a modificação do ambiente pela sua própria inserção nele até o efetivo trabalho no bar, eventualmente), e esses o faziam com gosto, ao passo em que compreendiam que a casa possibilitava experiências ímpares dentro do contexto da música eletrônica portenha, pontuadas, ao mesmo tempo, pela liberdade, e pela intimidade (de quem se sente em casa).

O último capítulo do livro, intitulado "Mezcla, trama social y formación de nuevas practicas musicales en Buenos Aires”, dedicado à pesquisa realizada por Victoria Irisarri junto ao coletivo de músicos ZIZEK, também de Buenos Aires, apresenta-nos a dimensão da mistura no contexto dos empreendimentos musicais contemporâneos daquela cidade. Irisarri encontra nas trajetórias dos produtores musicais 
do mencionado coletivo, caracterizadas pela "omnivoridade musical", a trilha para o que resultará no esmaecimento (da importância) dos gêneros musicais naquela cena. Ali, os sujeitos, antes de se especializarem em um gênero específico e sobre ele construírem verticalmente suas trajetórias, possuem histórias de gostos com trânsito por diferentes musicalidades, sendo a busca pelo novo e o experimentalismo valores altamente reputados. Daí que o instrumental analítico oferecido por Pierre Bourdieu (2007) em seu trabalho sobre gosto, fortemente vinculado ao conceito de classe, acabe saindo prejudicado em um contexto de atomização dos próprios gostos, cada vez mais compósitos e heteróclitos. Mesmo a ideia de "música" tal como subentendida na expressão "gosto musical” precisaria ser revista, uma vez que os DJs/produtores com quem Irisarri trabalha manipulam sonoridades mais comumente entendidas como ruidos, tais como aquelas componentes dos soundscapes das grandes cidades, na composição de novas obras. É o domínio de amplos repertórios sonoros/musicais que permite aos atores a criação de obras originais, através de processos como os de desconstrução, recomposição, sobreposição e fragmentação de músicas já existentes, encontrados, por exemplo, nos mashups e nos remixes. Se na cena indie platense as delimitações entre os papéis de músicos e administradores se desfaz, aqui isso não apenas se repete, mas a própria ideia do produtor de música se desloca em direção a uma espécie de audiência hiper-qualificada capaz de agenciar músicas e sons produzidos por outrem (sejam músicos, objetos, máquinas, eventos, etc.) na produção de peças originais, se afastando da imagem do músico, convencionalmente entendido como um operador de instrumentos musicais.

O capítulo de autoria de Victoria Irisarri mostra a recorrência de algumas das questões já levantadas nos trabalhos de Boix e Gallo. A centralidade das relações de amizade que, no entanto, antes de se constituírem por laços afetivos, passam pelo compartilhamento de gostos estético-culturais e musicais é uma delas, e nos aponta novamente para a vitalidade desse tipo de relações nos contextos de sociabilidade juvenil. Muito mais que o compartilhamento do ócio e do lazer, os laços de amizade possibilitam a formação de redes que, quando associadas às disposições artísticas e empreendedoras dos sujeitos, por sua vez viabilizam o agenciamento do ócio e do lazer para atividades economicamente viáveis. Assemelhando-se aos dois outros casos estudados, as atividades do coletivo ZIZEK se caracterizam pela busca de um equilíbrio entre o que parece ser a qualidade da experiência das festas e a oferta dessas como uma opção dentro de um mercado de entretenimento noturno.

Trata-se de uma obra muito bem-vinda a todos os interessados em temas como consumo cultural e empreendimentos juvenis. Já são bastante conhecidas as formas como as atuais gerações vêm redefinindo os limites entre áreas como trabalho, diversão, amizade, afeto, indivíduo e coletivo em empreendimentos que carregam sempre a marca da novidade. Gestionar, mezclar, habitar vem contribuir etnograficamente para a compreensão desse fenômeno.

Elton Colini Gonçalves Zimmermann é mestre e doutorando em Antropologia pelo Programa de Pós-graduação em Antropologia e Arqueologia da Universidade Federal do Paraná (UFPR).

RECEBIDO: $14 / 08 / 2020$

APROVADO: $20 / 09 / 2020$ 